\title{
Evidence for More Than One Mechanism of Plasmid-determined Tetracycline Resistance in Escherichia coli
}

\author{
By STUART W. SHALES, IAN CHOPRA* AND PETER R. BALL \\ Department of Bacteriology, University of Bristol, Bristol BS8 1TD
}

(Received 2 April 1980)

\begin{abstract}
The basis of tetracycline resistance mediated by TetA determinants and joint resistance to tetracycline and minocycline coded by TetB determinants was investigated. The TetA class of determinants was represented by those carried on plasmids pSC101, RP1 and pIP7 and TetB by Tn10. The relationships between expression of tetracycline and minocycline resistance and accumulation of these antibiotics suggest that there are three mechanisms of plasmid-determined resistance conferring (1) about a 10- to 20-fold increase in resistance to tetracycline that is not associated with decreased antibiotic accumulation, (2) a 4- to 7-fold increase in resistance to tetracycline that is associated with decreased drug accumulation, and (3) about a 2- to 3-fold increase in resistance to both tetracycline and minocycline that is not associated with decreased accumulation of either antibiotic. Mechanism 1 was coded by the tetracycline resistance determinant of pSC101 (TetA), mechanisms 1 and 2 by the determinants in RP1 and pIP7 (TetA) and all three mechanisms by Tn10 (TetB).
\end{abstract}

\section{INTRODUCTION}

Bacterial resistance to the tetracyclines is widespread and in many species the genes specifying resistance are plasmid-located (Bukhari et al., 1977). Although a spectrum of phenotypes exists, it is possible to divide the plasmids conferring tetracycline resistance in enteric bacteria into two categories depending on the relative protection they give against tetracycline and minocycline (Foster \& Walsh, 1974; Chabbert \& Scavizzi, 1976). The two classes have been designated TetA and TetB by Chabbert \& Scavizzi (1976). Plasmids of the TetA category determine resistance to tetracycline but little resistance to the tetracycline derivative minocycline, whereas plasmids of the TetB category specify resistance to both compounds.

Expression of tetracycline resistance determined by both classes of plasmid is usually inducible and probably involves a system of negative regulatory control (see Chopra \& Howe, 1978). However, transcriptional control of a single operon seems unlikely in view of recent findings by Tait \& Boyer (1978a) and Beck (1979). Chabbert \& Scavizzi (1976) suggested that TetA-mediated resistance is due to exclusion of tetracycline from the cell, whereas TetB-mediated resistance may result solely from modification of the $30 \mathrm{~S}$ ribosomal subunit. However, R100-1, which confers resistance to both tetracycline and minocycline (Foster \& Walsh, 1974) and may therefore be classified as TetB, determines cell envelope changes which, at least for tetracycline, reduce uptake of the antibiotic (see Chopra \& Howe, 1978). TetB-determined resistance may therefore be mediated by two distinct resistance mechanisms only one of which involves decreased accumulation of antibiotic, whereas TetA plasmids may only encode reduced tetracycline uptake. We have examined tetracycline and minocycline uptake in strains of $E$. coli carrying TetA and TetB determinants on the assumption that the proposed resistance mechanisms might be distinguished from each other by accumulation kinetics. A preliminary account of part of this work has already been published (Ball et al., 1979). 
Table 1. Escherichia coli K12 strains and plasmids

Strain no. Strain description

Reference

JC3272

UB1528

UB1529

UB1553

UB5759

UB5789

DU1200

his trp mal gal lys lac $\Delta X 74 \lambda^{\mathrm{r}} \mathrm{T}^{\mathrm{r}} \mathrm{Str}^{\mathrm{r}} \mathrm{Spc}^{\star}$ rec $^{+} \mathrm{F}^{-}$ JC3272(pIP7)*

JC3272(pIP69)*

JC3272(pDU301) $\dagger$

$\mathrm{JC} 3272(\mathrm{pSC101}) \ddagger$

JC3272(RP1)§

Derived by transposition of the tetracycline resistance region of pDU 300 to the chromosome of JC3272

DU3091 Derived by transposition of the tetracycline resistance region of R100-1 to the chromosome of JC3272

* Plasmids pIP7 (TetA Km Sm Su) and pIP69 (TetB Km Cb) (Scavizzi, 1972) were obtained from Y. A. Chabbert, Institut Pasteur, Paris.

$\dagger$ pDU301 and pDU300 are mutants of R100-1 which express tetracycline resistance constitutively.

$\$$ pSC101 was obtained from Hashimoto \& Sekiguchi (1976) and transferred to JC3272 by transformation.

$\S$ Plasmid RP1 (Tet Km Cb) was first described by Grinsted et al. (1972).

\section{METHODS}

Bacterial strains and plasmids. These are listed in Table 1.

Growth media. Liquid cultures were grown in Difco nutrient broth (Chopra et al., 1977). Nutrient agar comprised the above medium with the addition of Difco Bacto-agar $(2 \%, \mathrm{w} / \mathrm{v})$.

Chemicals. Tetracycline was from Sigma. Minocycline (9-dimethylamino-6-demethyl-6-deoxytetracycline) was a gift from Lederle Laboratories, Gosport, Hants. Other chemicals were the purest commercially available.

Determination of minimum inhibitory concentrations of tetracycline and minocycline. Aerated cultures were grown for $18 \mathrm{~h}$ in nutrient broth. Cultures were supplemented with tetracycline $\left(0.5 \mu \mathrm{g} \mathrm{ml}^{-1}\right)$ for experiments on induction. Samples $(0.02 \mathrm{ml})$ of a $10^{-6}$ dilution (sufficient to give discrete single colonies) were placed on plates containing dilutions of antibiotic, and the lowest concentration completely inhibiting growth (m.i.c.) was recorded after overnight incubation.

Determination of concentrations of tetracycline and minocycline causing a $50 \%$ reduction in growth rate $\left(I C_{50}\right)$. Bacteria $\left(1 \times 10^{8}\right.$ to $\left.2 \times 10^{8} \mathrm{ml}^{-1}\right)$ growing exponentially at $37^{\circ} \mathrm{C}$ in nutrient broth were challenged with various concentrations of tetracycline or minocycline. Semi-logarithmic plots of culture turbidity versus time gave biphasic curves in the inhibited cultures which were similar to those previously reported for $E$. coli (Brown \& Garrett, 1964). The secondary phase is considered to represent the steady state in response to inhibition by tetracyclines (Heman-Ackah, 1976) and, accordingly, the growth rates during the secondary phase were used to determine the $\mathrm{IC}_{50}$ values.

Estimation of plasmid (CCC) DNA contents. Bacteria were labelled with [methyl- ${ }^{3} \mathrm{H}$ ] thymidine and covalently closed circular (CCC) DNA was separated from chromosomal DNA according to Grinsted et al. (1972). Percentage CCC DNA contents were estimated as described by Chopra et al. (1973). Since this assay measures only CCC DNA, and no other forms of plasmid DNA (e.g. relaxation complexes), the copy number value should be taken as a minimum estimate. Plasmid size was determined as described by Robinson et al. (1977).

Accumulation of tetracycline and minocycline by bacteria. Uptake of tetracycline and minocycline was determined by fluorescence spectroscopy. Mid-exponential phase bacteria were harvested by centrifugation $\left(30^{\circ} \mathrm{C}, 12000 \mathrm{~g}, 10 \mathrm{~min}\right)$ washed and resuspended $\left(5 \times 10^{\circ}\right.$ cells $\left.\mathrm{ml}^{-1}\right)$ in a Tris $/ \mathrm{HCl}$ buffer $(10 \mathrm{~mm}, \mathrm{pH} 8 \cdot 0)$ containing glucose $(0.4 \%, \mathrm{w} / \mathrm{v})$. Tetracycline or minocycline (each at $100 \mu \mathrm{g} \mathrm{ml}^{-1}$ ) was added and fluorescence enhancement was monitored at $37^{\circ} \mathrm{C}$ in a Perkin-Elmer 3000 spectrofluorimeter (see Fig. 1). Bacteria were aerated throughout the course of each experiment by circulating the cell suspension through a flow cell $(1 \mathrm{~cm}$ light path). Fluorescence of tetracycline was measured at $520 \mathrm{~nm}$ (slit width $5 \mathrm{~nm}$ ) following excitation at $400 \mathrm{~nm}$ (slit width $5 \mathrm{~nm}$ ). Fluorescence of minocycline was measured at $450 \mathrm{~nm}$ following excitation at $315 \mathrm{~nm}$ (slit widths as above). For tetracycline accumulation the signal from the spectrofluorimeter was fed directly to a chart recorder. However, minocycline fluorescence was measured by signal averaging because of the poor signal to noise ratio using this antibiotic.

The relationship between fluorescence enhancement and the absolute amounts of tetracycline and minocycline accumulated by strain JC3272 (see Fig. 2) was determined as follows. Bacteria grown, washed and resuspended as above $\left(5 \times 10^{9} \mathrm{ml}^{-1}\right)$ were incubated with tetracycline $\left(100 \mu \mathrm{g} \mathrm{ml}^{-1}\right)$ or minocycline $(100 \mu \mathrm{g}$ $\mathrm{ml}^{-1}$ ). Fluorescence of tetracycline or minocycline was monitored continuously in the spectrofluorimeter 


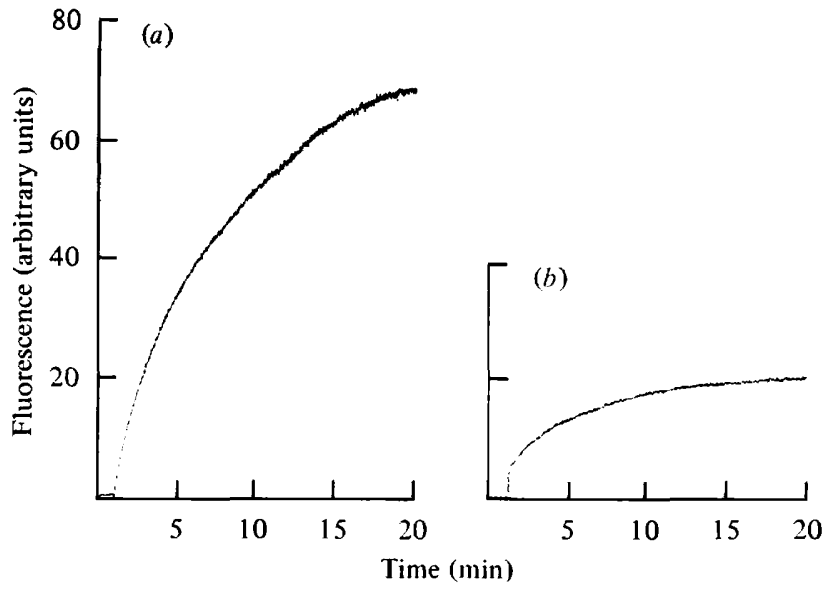

Fig. 1. Time-dependent fluorescence enhancement of tetracycline in suspensions of strains JC3272 (a) and UB1528 induced with tetracycline $\left(0.5 \mu \mathrm{g} \mathrm{ml}^{-1}\right)$ during growth $(b)$. Bacteria $\left(5 \times 10^{9} \mathrm{ml}^{-1}\right)$ suspended in a Tris buffer containing glucose (see Methods) were incubated aerobically at $37^{\circ} \mathrm{C}$ with tetracycline $\left(100 \mu \mathrm{g} \mathrm{ml}^{-1}\right)$ and fluorescence enhancement was determined as described in Methods.

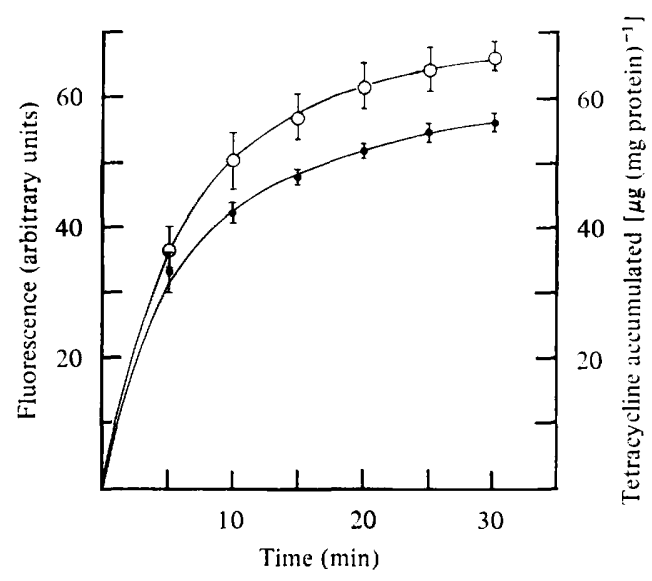

Fig. 2. Comparison of time-dependent fluorescence enhancement $(O)$ and uptake $(O)$ of tetracycline by strain JC3272. Bacteria $\left(5 \times 10^{9} \mathrm{ml}^{-1}\right)$ were incubated with tetracycline as described in Fig. 1. Simultaneous fluorescence enhancement and uptake of tetracycline were measured as described in Methods. Indicated values are the means of four replicates and the error bars represent \pm 1 standard deviation.

and samples were removed at intervals from the circulating cell suspensions to determine cell-associated antibiotic and total bacterial protein. Bacteria to be used for estimation of cell-associated tetracycline or minocycline were sedimented rapidly by centrifugation and then treated as follows. Tetracycline was extracted and converted to anhydrotetracycline by heating $\left(100{ }^{\circ} \mathrm{C}, 5 \mathrm{~min}\right)$ in $\mathrm{HCl}(18 \%, \mathrm{w} / \mathrm{v})$. Absorbance at $440 \mathrm{~nm}$ was determined against a blank of acid-treated bacteria (lacking added tetracycline). Levels of tetracycline were quantified from standard curves constructed using known amounts (0 to $100 \mu \mathrm{g})$ of anhydrotetracycline. Further details of this assay have been described elsewhere (Mitscher, 1978). Extraction of minocycline with $\mathrm{HCl}$ does not form a suitable basis for minocycline assay since there is no anhydro derivative of this antibiotic (Mitscher, 1978) and acid treatment leads to loss of absorbance at $440 \mathrm{~nm}$. Bacterial pellets were therefore solubilized by heating $\left(100^{\circ} \mathrm{C}, 10 \mathrm{~min}\right)$ in sodium dodecyl sulphate (SDS; $10 \%, \mathrm{w} / \mathrm{v}$ ) and minocycline was quantified by determination of absorbance at $440 \mathrm{~nm}$. Standard curves were constructed from samples of minocycline $(0$ to $100 \mu \mathrm{g})$ heated in SDS. 
Table 2. Molecular weight and mean number of copies per chromosome of plasmids pIP7, pIP69, pDU301 and RP1

$\begin{array}{clccc}\text { Strain } & \text { Plasmid } & \begin{array}{c}10^{-6} \times \\ \text { Plasmid } \\ \text { mol. wt }\end{array} & \begin{array}{c}\text { Plasmid content } \\ \text { (\% CCC DNA) }\end{array} & \begin{array}{c}\text { Mean no. of } \\ \text { plasmid copies } \\ \text { per }\end{array} \\ \text { UB1528 } & \text { pIP7 } & 47^{*} & 3 \cdot 8 & 2 \\ \text { UB1529 } & \text { pIP69 } & 48^{*} & 2 \cdot 7 & 1 \\ \text { UB5789 } & \text { RP1 } & 38^{*} & 3 \cdot 3 & 2 \\ \text { UB1553 } & \text { pDU301 } & 70 \dagger & 3 \cdot 1 & 1\end{array}$

* From P. M. Bennett (personal communication).

$\dagger$ From Bukhari et al. (1977).

$\ddagger$ Determined on cultures unexposed to tetracycline; results are the means of at least three replicate determinations for each strain.

$\S$ Calculated from the following information: the quoted molecular weight for each plasmid; the percentage of CCC DNA; a molecular weight of $2.5 \times 10^{9}$ for the E. coli chromosome.

Table 3. Resistance profiles to tetracycline and minocycline of induced and uninduced cultures of $E$. coli $\mathrm{K} 12$

\begin{tabular}{|c|c|c|c|c|c|}
\hline \multirow[b]{2}{*}{ Strain } & \multirow[b]{2}{*}{ Plasmid } & \multicolumn{2}{|c|}{$\begin{array}{c}\text { Tetracycline m.i.c.* } \\
\left(\mu \mathrm{g} \mathrm{ml}^{-1}\right)\end{array}$} & \multicolumn{2}{|c|}{$\begin{array}{c}\text { Minocycline m.i.c.* } \\
\left(\mu \mathrm{g} \mathrm{ml}^{-1}\right)\end{array}$} \\
\hline & & Uninduced & Induced $t$ & Uninduced & Induced \\
\hline $\mathrm{JC} 3272$ & - & 2 & 2 & 3 & 3 \\
\hline UB1528 & pIP7 & 75 & $100-200$ & 3 & 3 \\
\hline UB1529 & pIP69 & 100 & $100-200$ & 20 & 20 \\
\hline UB5759 & pSC101 & 25 & 50 & 3 & 3 \\
\hline UB5789 & RP1 & 16 & 64 & 3 & 3 \\
\hline DU1200 & - & 150 & 150 & 20 & 20 \\
\hline
\end{tabular}

* Minimum concentration that totally inhibits growth.

$\uparrow$ Strains were induced by pre-growth in nutrient broth containing $0 \cdot 5 \mu \mathrm{g}$ tetracycline $\mathrm{ml}^{-1}$.

\section{RESULTS}

\section{Plasmid copy numbers}

Plasmid pSC101 is present at six to eight copies per chromosome (Bukhari et al., 1977). Since there is little published information on the number of copies per chromosome of the other plasmids used here, we determined these values (Table 2). Both pIP69 and pDU301 were present at one copy per chromosome, whereas pIP7 and RP1 were present at two copies per chromosome.

\section{Resistance profiles to tetracycline and minocycline in various strains of E. coli $\mathrm{K} 12$}

Plasmids pIP7, RP1 and pSC101 are examples of TetA plasmids as defined by Chabbert \& Scavizzi (1976) since they mediate resistance to tetracycline but not to minocycline (Table 3). Expression of tetracycline resistance by these plasmids is inducible (Table 3), confirming previous observations (Foster \& Walsh, 1974; Chabbert \& Scavizzi, 1976; Tait $\&$ Boyer, 1978b). The induced level of tetracycline resistance mediated by pSC101 was lower than for the other determinants studied here (Table 3, Fig. 3). This cannot be attributed to a lower number of copies per chromosome for pSC101 (see above). Expression of pIP69-mediated tetracycline resistance is also inducible (Table 3, Fig. 3), and, unlike pIP7 or pSC101, pIP69 confers resistance to both tetracycline and minocycline, reflecting the reported differences in expression of resistance by TetA and TetB plasmids. Escherichia coli DU1200 contains a chromosomally integrated derivative of Tn10 in which expression of tetracycline resistance is constitutive (Foster, 1977). The constitutive phenotype was con- 


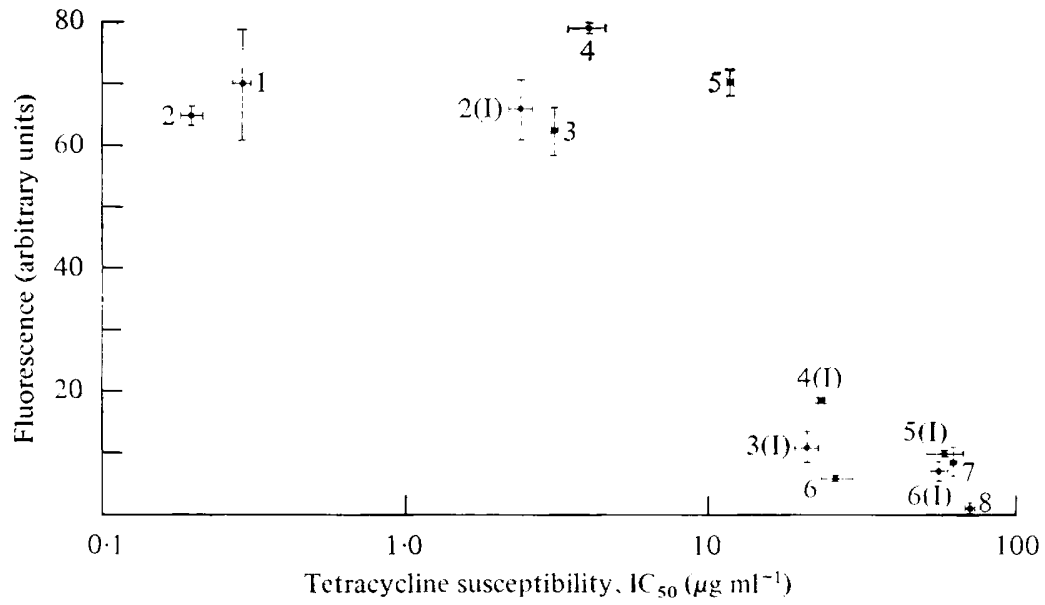

Fig. 3. Relationship between intracellular equilibrium concentration of tetracycline and resistance level in strains of $E$. coli K12. Intracellular tetracycline concentrations (arbitrary units) were determined from the plateau values of fluorescence enhancement curves following incubation of cell suspensions $\left(5 \times 10^{9}\right.$ bacteria $\left.\mathrm{ml}^{-1}\right)$ with tetracycline as described in Methods. Resistance levels $\left(\mathrm{IC}_{50}\right)$ to tetracycline were determined as described in Methods. Error bars represent \pm 1 standard deviation. Strains: 1, JC3272; 2, UB5759; 2(I), UB5759 induced with tetracycline $(0 \cdot 1 \mu \mathrm{g}$ $\mathrm{ml}^{-1}$ ) during growth; 3, UB1528; 3(I), UB1528 induced with tetracycline $\left(0.5 \mu \mathrm{g} \mathrm{ml}^{-1}\right)$ during growth; 4, UB5789; 4(I), UB5789 induced with tetracycline $\left(0.5 \mu \mathrm{g} \mathrm{mI}^{-1}\right)$ during growth; 5 , DU3091; 5(I), DU3091 induced with tetracycline $\left(0.5 \mu \mathrm{g} \mathrm{ml}^{-1}\right)$ during growth; 6, UB1529; 6(I), UB1529 induced with tetracycline $\left(0 \cdot 5 \mu \mathrm{g} \mathrm{ml}^{-1}\right)$ during growth; 7 , UB1553; 8, DU1200.

firmed in the present studies (Table 3). In addition, DU1200 is resistant to minocycline (Table 3), consistent with the possession of genes originating on R100-1, itself classified as a TetB element (see Foster \& Walsh, 1974).

It will be noted that different induction ratios (i.e. induced resistance level : basal resistance level) were obtained for some of the determinants when resistance levels were determined on solid media as opposed to liquid culture. This discrepancy relates primarily to the difficulty in estimating 'basal' resistance levels on solid media because induction occurs during colony formation.

\section{Accumulation of tetracycline by organisms harbouring Tet $A$ and Tet $B$ determinants}

Tetracycline can be used as a fluorescent probe of its own accumulation by bacteria (Dockter \& Magnuson, 1974, 1975; Weckesser \& Magnuson, 1976, 1979). Typical uptake curves for E. coli using this method are shown in Fig. 1. Previous studies with Staphylococcus aureus (Dockter \& Magnuson, 1974, 1975) and Rhodopseudomonas sphaeroides (Weckesser $\&$ Magnuson, 1976, 1979) demonstrated that the plateau value from a fluorescence curve provides an estimate of the intracellular equilibrium concentration of tetracycline. We confirmed that fluorescence enhancement also monitors tetracycline accumulation in $E$. coli (Fig. 2).

No simple relationship was observed between expression of tetracycline resistance mediated by TetA and TetB elements and the level of accumulated drug (Fig. 3). The TetA determinants in pIP7 and RP1 and the chromosomally integrated Tn10 element in strain DU3091 conferred basal levels of resistance that were not associated with decreased accumulation of tetracycline (Fig. 3). Expression of inducible resistance by all these determinants was associated with a 4- to 7-fold reduction in the level of accumulated antibiotic. Plasmid pSC101 did not confer a basal level of resistance and induction was not associated with decreased antibiotic accumulation (Fig. 3). Plasmid pIP69 conferred a basal level of resistance that resulted at least partially from decreased antibiotic accumulation since bacteria 
Table 4. Susceptibility of various strains of E. coli $\mathrm{K} 12$ to minocycline

$\begin{array}{ccc}\text { Snduction with } & \begin{array}{c}\text { Resistance level } \\ \left(\text { IC }_{50}\right) \text { to } \\ \text { minocycline* } \\ \left(\mu \mathrm{g} \mathrm{ml}^{-1}\right)\end{array} \\ \text { Strain } & \left(0.5 \mu \mathrm{g} \mathrm{ml}^{-1}\right) & 0.42 \pm 0.08 \\ \text { JC3272 } & - & 0.37 \pm 0.04 \\ \text { UB1528 } & + & 0.45 \pm 0.01 \\ & - & 0.41 \pm 0.08 \\ \text { UB5789 } & + & 0.67 \pm 0.03 \\ & - & 1.53 \pm 0.01 \\ \text { UB1529 } & + & 4.75 \pm 1.06 \\ & - & 0.76 \pm 0.17 \\ \text { DU3091 } & + & 2.13 \pm 0.18\end{array}$

* Mean values \pm 1 standard deviation.

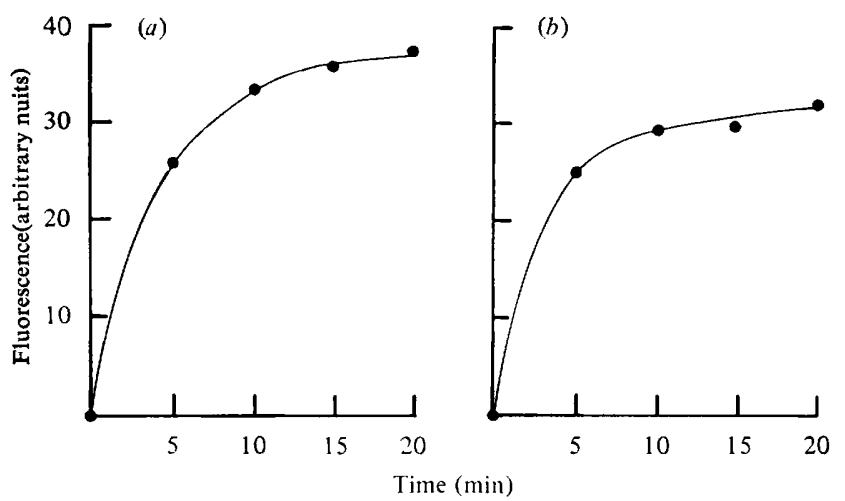

Fig. 4. Time-dependent fluorescence enhancement of minocycline in suspensions of strains JC3272 (a) and DU1200 (b). Bacteria $\left(5 \times 10^{9} \mathrm{ml}^{-1}\right)$ suspended in a Tris buffer containing glucose (see Methods) were incubated aerobically at $37^{\circ} \mathrm{C}$ with minocycline $\left(100 \mu \mathrm{g} \mathrm{ml}^{-1}\right)$ and fluorescence enhancement was determined as described in Methods.

containing the plasmid only accumulated about one-sixth of the tetracycline accumulated by the plasmidless host JC3272 (Fig. 3). The level of pIP69-mediated resistance was increased about 2-fold following induction, but this was not associated with decreased drug accumulation (Fig. 3). Strains possessing derivatives of Tn10 in which expression of resistance was constitutive (UB1553 and DU1200) accumulated levels of tetracycline similar to those in induced cultures of DU3091 (Fig. 3).

\section{Evidence that TetB-mediated minocycline resistance does not result from decreased drug accumulation}

Exposure of bacteria harbouring pIP7 or RP1 to sub-inhibitory levels of tetracycline only slightly enhanced the level of resistance to minocycline (Table 4) suggesting that the inducible mechanism involving decreased tetracycline accumulation (Fig. 3) was virtually ineffective against minocycline. Induction with tetracycline of cells harbouring pIP69 led to a 2- to 3-fold increase in resistance to both drugs (Table 4 and Fig. 3). On the basis of the results for tetracycline accumulation (Fig. 3) this inducible resistance to minocycline presumably did not result from decreased accumulation of drug. These observations suggest that the mechanism which mediates decreased accumulation of tetracycline in strain DU3091 might be ineffective against minocycline. In this case, expression of minocycline 
resistance in DU3091 following exposure to tetracycline would be due to a second, inducible mechanism analogous to that induced in UB1529. If this contention is correct then induced cultures of DU3091 should be 2- to 3-fold more resistant to minocycline than uninduced cultures. This is indeed the case (Table 4).

Direct evidence that the Tn10-specified mechanism involving decreased tetracycline accumulation is inoperative against minocycline was provided by determining the rate and level of minocycline accumulation. Although Samra et al. (1978) were unable to monitor minocycline accumulation by fluorescence, we have successfully followed its uptake into E. coli (Fig. 4) by this method. However, the fluorescence enhancement upon binding of minocycline to sensitive cells was approximately 30 -fold less than that obtained with equimolar concentrations of tetracycline. As for tetracycline, accumulation of minocycline was directly correlated with the time-dependent fluorescence enhancement (results not shown). Strain DU1200, which contains a mutant of Tn10 in which expression of tetracycline resistance is constitutive, accumulated minocycline to the same concentration as strain JC3272 (parent of DU1200) (Fig. 4). Mean intracellular equilibrium values were $32 \cdot 1 \pm 6 \cdot 3$ fluorescence units for DU1200 (4 determinations) and $36.9 \pm 4.8$ fluorescence units for JC3272 (4 determinations) $(t=1 \cdot 1, P \geqslant 0 \cdot 3$ ).

\section{DISCUSSION}

Recent studies in this laboratory (P. M. Bennett, S. J. Eccles \& T. G. B. Howe, unpublished results) have shown that the tetracycline resistance determinant in pIP69 is located in a transposon whose tetracycline resistance genes are probably identical to those in Tn10. However, results presented here show that expression of pIP69-mediated resistance does differ from that determined by Tn10 in strain DU3091 since the former conferred a higher level of basal (non-induced) resistance to tetracycline. This could result from greater synthesis of repressor in DU3091. Alternatively, since Tn10 contains three resistance genes, two of which are subject to independent regulatory control by the repressor (Beck, 1979), pIP69 could contain a derivative of Tn10 in which expression of two of the three resistance genes is constitutive. Results presented in Fig. 3 and discussed below favour the latter hypothesis.

As noted in the Introduction, Beck (1979 and personal communication) identified three Tn10 genes involved in resistance in addition to the gene specifying the repressor. If our contention that the resistance genes in Tn10 and pIP69 are identical is correct, then the products of the three genes can be related to independent resistance mechanisms as follows:

(a) A mechanism (1) that confers about a 10- to 20-fold increase in resistance to tetracycline and is not associated with decreased antibiotic accumulation. This mechanism is expressed constitutively by the wild-type Tn10 elements examined here and is most clearly shown by the results for DU3091.

(b) A mechanism (2) which results in reduced tetracycline accumulation. This mechanism (together with 1) is expressed constitutively by pIP69 but is inducible in DU3091.

(c) A mechanism (3) that confers about a 2- to 3-fold increase in resistance to tetracycline but is not associated with decreased accumulation of antibiotic. Only mechanism 3 is substantially inducible in cells containing pIP69, but mechanisms 2 and 3 are inducible in strain DU3091.

The extent to which mechanisms 1,2 and 3 confer protection against minocycline can be deduced from results presented in Tables 3 and 4 and Fig. 4. Mechanism 3 affords protection against both minocycline and tetracycline because its induction in UB1529 leads to a 2- to 3-fold increase in the level of resistance to both antibiotics. Mechanism 2, involving decreased tetracycline accumulation, is unlikely to provide protection against minocycline because strain DU1200 (in which expression of Tn10-mediated resistance is constitutive) accumulated equivalent amounts of minocycline to the tetracycline-sensitive host strain 
JC3272. That mechanism 2 is ineffective against minocycline suggests that tetracycline and minocycline have different routes of entry across the $E$. coli envelope. Indeed, there are data supporting different routes of entry (Del Bene \& Rogers, 1975; Ball et al., 1977; I. Chopra, S. W. Shales \& P. R. Ball, unpublished results). Uninduced cultures of both DU1200 and UB1529 showed some resistance to minocycline suggesting that mechanism 1 may confer some protection against minocycline. Alternatively, these results could reflect basal expression of mechanism 3.

The molecular bases of the resistance mechanisms are unclear. Mechanism 2 may be mediated by a 36000 dalton envelope protein whose synthesis in cells harbouring Tn10 is inducible (Levy \& McMurry, 1974). Mechanisms 1 and 3 may result from intracellular protection of ribosomes. Hirashima et al. (1973) showed that protein synthesis directed by membrane-bound polysomes is particularly susceptible to inhibition by tetracycline. In contrast, our own preliminary results indicate that these ribosomes are intrinsically insusceptible to inhibition by minocycline compared with cytoplasmic ribosomes. Mechanism 1 (conferring tetracycline resistance) might therefore result from protection of membranebound ribosomes and mechanism 3 (conferring joint minocycline and tetracycline resistance) from protection of cytoplasmic ribosomes. In this context, Levy and co-workers (Levy et al., 1977; Levy \& McMurry, 1978) have already suggested that Tn10-mediated resistance results partially from protection of ribosomes.

Mechanisms analogous to 1 and 2 also appear to be determined by the TetA plasmids RP1 and pIP7. It is not known whether these mechanisms are coded by homologous genes in the two plasmids, nor whether the products are related to those specified by $\operatorname{Tn} 10$. The products of pSC101 involved in tetracycline resistance are, however, unrelated to those coded by Tn10 (see Chopra \& Howe, 1978). Resistance mediated by pSC101 has been reported to involve decreased accumulation of antibiotic (Tait \& Boyer, 1978b). However, we have been unable to correlate expression of pSC101-mediated resistance with reduced tetracycline uptake using the fluorimetric assay (Fig. 3). The reason for the discrepancy between our results and those of Tait \& Boyer $(1978 b)$ is unclear, but might relate to the use of $\left[{ }^{3} \mathrm{H}\right]$ tetracycline in Tait \& Boyer's accumulation studies. Indeed, Levy et al. (1977) reported that self-radiolysis of tetracycline produces degradation products that bind to bacteria. Despite this conflicting evidence on the nature of pSC101-mediated resistance we can conclude that the TetB phenotype results from a mechanism (3) not coded by TetA elements. As noted above, this mechanism may involve intracellular protection of ribosomes so that Chabbert \& Scavizzi's (1976) earlier suggestion that TetB-mediated resistance results from ribosomal changes may be partially true.

We thank Mrs E. Barratt for excellent technical assistance. This work was supported by Medical Research Council project grants G975 1004C, G978 8345 and G978 67SB to I.C.

\section{REFERENCES}

Achtman, M., Willettis, N. \& Clark, A. J. (1971). Beginning a genetic analysis of conjugational transfer determined by the $\mathrm{F}$ factor in Escherichia coli by isolation and characterization of transferdeficient mutants. Journal of Bacteriology 106, 529-538.

Ball, P. R., Chopra, I. \& Eccles, S. J. (1977). Accumulation of tetracyclines by Escherichia coli K-12. Biochemical and Biophysical Research Communications 77, 1500-1507.

Ball, P. R., Shales, S. W. \& Chopra, I. (1979). Evidence for two mechanisms involved in plasmidmediated tetracycline resistance. Society for General Microbiology Quarterly 6, 149.
BECK, C. F. (1979). A genetic approach to the analysis of transposons. Proceedings of the National Academy of Sciences of the United States of America 76, 2376-2380.

Brown, M. R. W. \& GarretT, C. R. (1964). Kinetics and mechanisms of action of antibiotics. Reproducibility of Escherichia coli growth curves and dependence upon tetracycline concentrations. Journal of Pharmaceutical Sciences 53, 170-183.

Bukhari, A. I., Shapiro, J. L. \& Adhya, S. L. (1977), DNA Insertion Elements, Plasmids and Episomes. Cold Spring Harbor, New York: Cold Spring Harbor Laboratory.

Chabbert, Y. A. \& Scavizzi, M. R. (1976). Chelo- 
cardin-inducible resistance in Escherichia coli bearing $\mathbf{R}$ plasmids. Antimicrobial Agents and Chemotherapy 9, 36-41.

Chopra, I. \& Howe, T. G. B. (1978). Bacterial resistance to the tetracyclines. Microbiological Reviews 42, 707-724.

Chopra, I., Bennett, P. M. \& Lacey, R. W. (1973). A variety of staphylococcal plasmids present as multiple copies. Journal of General Microbiology 79, 343-345.

Chopra, I., Howe, T. G. B. \& Ball, P. R. (1977). Lysozyme-promoted association of protein I molecules in the outer membrane of Escherichia coli. Journal of Bacteriology 132, 411-418.

Del Bene, V. E. \& Rogers, M. (1975). Comparison of tetracycline and minocycline transport in Escherichia coli. Antimicrobial Agents and Chemotherapy 7, 801-806.

Dockter, M. E. \& Magnuson, J. A. (1974). Characterisation of the active transport of chlorotetracycline in Staphylococcus aureus by a fluorescence technique. Journal of Supramolecular Structure 2, 32-44.

Dockter, M. E. \& Magnuson, J. A. (1975). Membrane phase transitions and the transport of chlorotetracycline. Archives of Biochemistry and Biophysics 168, 81-88.

Foster, T. J. (1977). Isolation and characterisation of mutants of R100-1 which express tetracycline resistance constitutively. FEMS Microbiology Letters 2, 271-274.

Foster, T. J. \& Walsh, A. (1974). Phenotypic characterisation of $\mathrm{R}$-factor tetracycline resistance determinants. Genetical Research 24, 333-343.

Foster, T. J., Howe, T. G. B. \& RICHMOND, K. M. V. (1975). Translocation of the tetracycline resistance determinant from $\mathrm{R} 100-1$ to the Escherichia coli chromosome. Journal of Bacteriology 124, 1153-1158.

Grinsted, J., SAunders, J. R., Ingram, L. C., SyKes, R. B. \& Richmond, M. H. (1972). Properties of an R factor which originated in Pseudomonas aeruginosa 1822. Journal of Bacteriology 110, 529-537.

Hashimoto, T. \& Sekiguchi, M. (1976). Isolation of temperature-sensitive mutants of $\mathrm{R}$ plasmid by in vitro mutagenesis with hydroxylamine. Journal of Bacteriology 127, 1561-1563.

Heman-ACKaH, S. M. (1976). Comparison of tetracycline action on Staphylococcus aureus and Escherichia coli by microbial kinetics. Antimicrobial Agents and Chemotherapy 10, 223-228.
Hirashima, A., Childs, G. \& Inouye, M. (1973). Differential inhibitory effects of antibiotics on the biosynthesis of envelope proteins in Escherichia coli. Journal of Molecular Biology 79, 373-389.

LEVY, S. B. \& MCMurRy, L. (1974). Detection of an inducible membrane protein associated with R-factor-mediated tetracycline resistance. Biochemical and Biophysical Research Communications 56, 1060-1068.

Levy, S. B. \& McMurry, L. (1978). Probing the expression of plasmid-mediated tetracycline resistance in Escherichia coli. In Microbiology 1978, pp. 177-180. Edited by D. Schlessinger. Washington, D.C.: American Society for Microbiology.

LeVy, S. B., McMurry, L., OnigmaN, P. \& SAUNDERS, R. M. (1977). Plasmid-mediated tetracycline resistance in Escherichia coli. In Topics in Infectious Diseases, vol. 2, pp. 181-203. Edited by J. Drews \& G. Hogenauer. New York: SpringerVerlag.

Mitscher, L. A. (1978). The Chemistry of the Tetracycline Antibiotics. Medicinal Research Series, vol. 9. New York \& Basel: Marcel Dekker.

Robinson, M. K., BennetT, P. M. \& Richmond, M. H. (1977). Inhibition of TnA translocation by TnA. Journal of Bacteriology 129, 407-414.

Samra, Z., KrauszsteinmetZ, J. \& Sompolinsky, D. (1978). Transport of tetracyclines through the bacterial cell membrane assayed by fluorescencestudy with susceptible and resistant strains of Staphylococcus aureus and Escherichia coli. Microbios 21, 7-22.

ScavizzI, M. R. (1972). Existence de deux caractères transferables de resistance aux tetracyclines. Annales de l'Institut Pasteur 122, 3-17.

TAIT, R. C. \& BOYER, H. W. (1978a). Restriction endonuclease mapping of pSC101 and pMB9. Molecular and General Genetics 164, 285-288.

TAIT, R. C. \& Boyer, H. W. $(1978 b)$. On the nature of tetracycline resistance controlled by the plasmid pSC101. Cell 13, 73-81.

Weckesser, J. \& Magnuson, J. A. (1976). Lightinduced tetracycline accumulation by Rhodopseudomonas sphaeroides.Journalof Supramolecular Structure 4, 515-520.

Weckesser, J. \& Magnuson, J. A. (1979). Lightinduced, carrier mediated transport of tetracycline by Rhodopseudomonas sphaeroides. Journal of Bacteriology 138, 678-683. 